\title{
Participatory Monitoring and Evaluation
}

\section{Tracking change together}

\author{
Irene Guijt, Mae Arevalo and Kiko Saladores
}

\section{- Introduction}

Monitoring progress and evaluating impacts have long been considered important to ensure that money is well spent and that objectives are met. Besides this conventional focus on being accountable to funding agencies, organisations are increasingly using monitoring and evaluation for internal learning and to improve their work. They see that, for maximum benefits, learning needs $\mathrm{t}$ happen collectively with diverse groups and people. Many of these organisations already work with participatory appraisal and planning, making it a logical step for them to also make their monitoring and evaluation processes more participatory (Estrella and Gaventa, 1997).

Much is already being claimed of participatory monitoring and evaluation (PM\&E): it is 'empowering', 'cost-effective', 'more accurate', 'more relevant', etc. However, too little is known about PM\&E to confirm these claims (Abbot and Guijt, 1998) and it is clear that many challenges are appearing. How do we make monitoring and evaluation (M\&E) more participatory - and maintain high levels of involvement? How does participation of diverse groups influence the selection of what we monitor or evaluate? What methods are feasible in which contexts? How do we use $\mathrm{PM} \& \mathrm{E}$ in hierarchical organisations and in conflict situations?

Despite such questions, many fascinating experiences exist that use innovative methods with enormously diverse groups of people to obtain very worthwhile results. A recent international workshop on PM\&E in the Philippines brought together dozens of inspiring examples from NGOs, government agencies, donors, community-based organisations, and research institutions. This issue of PLA Notes shares six experiences from the workshop, representing a range of purposes, organisational contexts, approaches, and methods. Our overview draws on the discussions at the workshop and other literature, and aims to share key innovations, issues, and challenges.

\section{What is PM\&E?}

As with other areas of participatory work, PM\&E has a huge range of interpretations. Quite surprisingly, even the difference between monitoring and evaluation remains unclear. Participants at the Philippines workshop were keen to reach a consensus on definitions but had to settle for more loose descriptions. Monitoring was associated with words such as: 'observing change'; 'knowing where we are now'; 'a kilometre check'; and 'regular, on-going assessment of activities and trends'. By comparison evaluation was described in terms of: 'valuing'; 'understanding'; 'periodic performance review'; 'reflection process to look back and foresee' and 'assessment of strategic issues, changes, achievements, and of impact (efficiency of programmes)'. In most contexts, both processes are linked and, as long as they are defined clearly by the organisation, there is no problem in having varying definitions throughout the world.

A key part of understanding PM\&E depends on how 'participation' is interpreted. This also has many different interpretations as each process, with its unique purpose and context, will involve different groups of people to varying degrees. Who participates and to what extent depends partly on the level of monitoring and evaluation. $\mathrm{PM} \& \mathrm{E}$ is not only related to community-based or 'farmer-driven' 
processes. In some cases, including junior staff in designing a monitoring form is making a process previously dominated by senior management a more participatory one.

For some, 'participatory' means involving all relevant groups in designing the entire $\mathrm{M} \& \mathrm{E}$ approach (Torres, this issue). It can mean having villagers help refine methods, as Rai discusses within his forestry work in Nepal, or define the main evaluation/monitoring objectives, as Bandre describes happened in the evaluation of a World Neighbors programme. In other examples, villagers participate by collecting data and helping to analyse the information. Despite the possible diversity, in many cases participation still means doing $\mathrm{M} \& \mathrm{E}$ with participatory methods within a standard project cycle, which remains extractive. There are far fewer cases of PM\&E, in which all parts of the process are opened up to greater participation.

That PM\&E can have many different purposes is also clear. Some use it as a research tool, for example, with farmers monitoring their own experiments and sharing the data with researchers. Others use it more as a project management activity, to assess how development objectives are being met (Rai, this issue), or for learning and organisational change (Symes and Jasser, this issue). Others again see it as a strategy for community empowerment (Torres and Bandre, this issue). In Australia, over 200 community groups are involved in participatory monitoring of birds, water, soil, etc., and use the information to advocate for better environmental regulation (Alexandra et al, 1995). Whether organisational self-assessment, citizen monitoring of government programmes, villagers monitoring externally driven projects, or resource users monitoring the state of their own environment, most experiences combine different purposes. Nevertheless, PM\&E to date appears to have met the information needs of organisations and institutions far more than those of communities. And most of the documented experiences are initiated by organisations, although many examples of indigenous monitoring exist (Abbot and Guijt 1998).

Given all this diversity, it is tempting to want to define the 'non-negotiable' core of PM\&E. Estrella and Gaventa (1997) limit themselves to four core principles: participation, learning, negotiation, and flexibility. Being more specific is difficult due to the great variation of circumstances in which $\mathrm{PM} \& \mathrm{E}$ is used. For example, how much community members want to be involved, or get the chance to be involved, will vary between more and less politically free countries and more or less hierarchical organisations (see Box 1). If we knew what the heart of PM\&E was, it would help to identify best practice and set standards. However, having no common definitions as yet and given that each situation is unique, the non-negotiable principles of $\mathrm{PM} \& \mathrm{E}$ are likely to be left general.

\section{- Innovations galore}

Participatory monitoring and evaluation is a methodological frontier, so it is not surprising that the workshop revealed many innovative experiences. The contributors to this issue show the exciting potential of PM\&E in many contexts. Rai discusses its use in joint forest management, Ara describes PM\&E within a disaster relief programme in Bangladesh, while Symes and Jasser share their experience of how it can help rebuild Palestinian civil society after conflict. Torres describes its use for assessing municipal level development projects in Ecuador and Bandre explains his experience with a district-wide NGO programme evaluation in Burkina Faso. Specific topics have been examined, such as assessing the impact of leadership training programmes (Abes this issue). Innovations have been also been made in the purpose and methods of PM\&E. 


\section{BOX 1}

\section{WHAT INFLUENCES PEOPLE'S PARTICIPATION IN MONITORING AND EVALUATION?}

- $\quad$ perceived benefits (and partial or short-term costs) of PM\&E

- $\quad$ relevance of PM\&E to the priorities of participating groups

- $\quad$ quick and relevant feedback of findings

- flexibility of the PM\&E process to deal with diverse and changing information needs

- meeting expectations that arise from PM\&E, such as acting on any recommendations that are made

- degree of maturity, capabilities, leadership, and identity of the groups involved, including their openness to sharing power

- local political history, as this influences society's openness to stakeholders' initiatives

- whether short term needs of participants are dealt with, while considering the longer term information needs of PM\&E (especially in natural resource management)

- $\quad$ incentives to make the PM\&E possible (e.g. pens, books, etc.)

\section{New purposes}

Besides fulfilling the conventional functions of monitoring and evaluation for project impact assessment and management/planning, more innovative use of PM\&E includes managing and resolving conflicts. Specific innovations include using PM\&E:

- to help ensure that project and programme impacts influence and reorient policy (see Torres, this issue);

- to strengthen self-development initiatives in villages (Bandre, this issue);

- for organisational strengthening and learning (Symes and Jasser; Rai, this issue);

- to provide public accountability of local and national government programmes to communities (Torres, this issue);

- to encourage institutional reform towards more participatory structures (Symes and Jasser, this issue);

- to encourage funding agencies to re-assess their objectives and attitudes by understanding and negotiating stakeholders' perspectives through PM\&E (Torres; Bandre, this issue);

- in the government sector (Rai this issue), as it has been mainly focused on the NGO sector to date; and,

- to build theories and check/adapt our understanding of society and development (Abes this issue).

\section{New methods}

Monitoring and evaluation by definition compares 'before and after' or 'with and without-project' situations. Therefore, to be able to make a meaningful comparison over time, a baseline of information needs to exist which describes the situation before any project or programme starts. This information is often collected in appraisal and planning stages (see Box 2).

To be able to make comparisons, existing appraisal or planning methods, which often simply describe one moment in time, need to be adapted or new methods need to be created. For example, imagine doing a transect walk to help assess what resources exist. For it to be useful to monitor changes in the amount or quality of resources, the transect diagram that is made should be able to store information from repeated transect walks over a six month period and therefore should be recorded on quite a large piece of paper. Alternatively, if each walk is to be recorded on a different sheet of paper, then these should be similar enough to make comparisons easy.

Problems arise when different kinds of information are collected during each walk, for example, if one focuses on the different types of pests that might be found while the next one looks at the extent of soil erosion. This is why most monitoring systems decide ahead of time what information, or 'indicators' will be observed or measured each time. In some cases, new methods need to be developed (see Box 3) for the different tasks of PM\&E. Monitoring and evaluation consists of many 
different tasks: data must be collected, registered, compiled, analysed and then shared again with those who are to use it. While the methods for collection may be similar to those used in appraisal and planning, as the transect example shows, much more thought has to go into finding the appropriate methods for each of these tasks (see Box 3). And when a monitoring and evaluation process becomes more participatory this usually means discussing and negotiating until agreement is reached, thus often leading to new methods!

\begin{abstract}
BOX 2
APPRAISALS TO FIND THE BASELINE FOR COMPARISON

The Aga Khan Rural Support Programme (AKRSP) is an Indian NGO that support local village institutions (VIs) to use their natural resources in a sustainable and equitable manner. AKRSP helps these VIs to carry out their own appraisals and plan their development priorities. As part of the preproject appraisal, local people prepare detailed maps of their village which incorporates their analysis about the available resources, how these are used, ownership, problems and constraints. These detailed maps represent an inventory of resource-related issues and are used as the basis for planning village projects. All the proposed activities are depicted on the maps, and include: soil and water conservation, minor irrigation, forest plantation and protection, etc. These maps are kept in the villages and are displayed in a convenient location that is accessible for all members of the VI. During meetings and project reviews, these maps are used to monitor the project activities and resolve problems.
\end{abstract}

Source: Kaul Shah, 1995.

\title{
BOX 3 \\ ADAPTING METHODS THROUGH PARTICIPATION
}

In central Brazil, farmers, NGO staff, farmers union representatives, and university academics are working on more sustainable forms of agriculture. They had chosen 'the percentage of vegetation cover' as one indicator for monitoring an agroforestry activity, and were identifying which method to use. Quite quickly they agreed on using a wooden frame to estimate visually the surface area covered by vegetation. But problems arose when deciding how that information should be recorded for easy comparison. The farmers rejected several forms suggested by the academics as too complicated. Finally, they all agreed on the use of a wooden ruler, on which the farmer would scratch a mark to indicate the estimated percentage of vegetation cover in terms of a certain segment of the ruler. Each farmer would get the same length stick twice a year, one for each time the vegetation cover would be monitored. To compile and analyse the information, the farmers involved in agroforestry would bring their marked rulers to a meeting, register the findings on paper, and discuss the findings and their significance for their agroforestry plots. By using a new stick for each measurement and recording the marks, they would be able to easily keep track of changes in vegetation cover.

Source: Guijt and Netto 1997, in Abbot and Guijt 1998. 
In other cases, non-participatory monitoring and evaluation methodologies already exist or are imposed by funding agencies but may need to be adapted to become more relevant for local information needs and learning. A good example is Logframe Analysis (LFA) which is used by many funding agencies who require the organisations they fund to use it but has been found inappropriate and too rigid for village use (see Symes and Jasser, this issue). LFA is slowly being adapted for use by communities for both planning and monitoring (Sewagudde et al, 1997). To do this, the stages are simplified, words are changed, and participatory methods are incorporated. Other methodological innovations include:

- merging different approaches, including social auditing; computer-based Geographic Information Systems (Torres, this issue); and psychological assessments (Abes, this issue);
- new applications of existing appraisal methods, for example wealth ranking for before and after project situations (Bandre, this issue); visualisation techniques for planning and review (Ara, this issue);

- entirely new methods, for example the Barometer of Sustainability used with villagers in India as part of an IUCN/IDRC approach for assessing progress towards sustainability (Chatterjee, 1997);

- methodologies not based on predetermined indicators but instead on openended questions (see Box 4);

- methods that consciously seek the unexpected (see Box 5), for example, impact flow diagrams that allow all kinds of impacts to be identified; and,

- building on culturally valid (not just culturally sensitive) frameworks, ways of monitoring and data collection (Abes this issue).

\section{MONITORING WITHOUT INDICATORS?}

A particularly innovative example has been developed within the Christian Commission for Development in Bangladesh (Davies, 1995). Each credit group funded by CCDB report, on a monthly basis, the single most significant change that occurred amongst the group members related to: people's well-being, sustainability of people's institutions, and people's participation, and one other open-ended change, if they wish. The report asks for the 'facts' (what, when, where, with whom) and an explanation of why that change is the most significant one of all the changes that have occurred. This last aspect ensures a process of reflection and learning by the group members, an aspect that is missing from most M\&E systems that seek numeric data without any interpretation of the numbers. So instead of pre-determined questions, CCDB's monitoring aims to find significant examples related to its long-term development objectives.

\section{BOX 5 \\ UNEXPECTED SUCCESSES!}

Villagers in the drought prone areas of Gujarat have, with AKRSP's support, constructed percolation tanks to recharge the water level in the wells. Unfortunately, the area experienced three consecutive drought years just as the first percolation tanks were finished in the late 1980s. Using the predetermined indicators, the village men concluded that the project had no impact at all: water levels in wells had not risen, cropping patterns had not changed and crop productivity had not increased. However, the women concluded that the project had been a lifeline, as the people living in the areas with percolation tanks had not run short of drinking water and had suffered no cattle mortality even in the worst drought conditions. While people from neighbouring villages had to migrate out in search of water ,they were able to stay put and to bathe and wash their clothes regularly - a luxury at that time. 


\section{- Issues emerging}

There is great diversity of PM\&E experiences, and the current rate of innovations will only add to that diversity. Nevertheless, four common themes stand out as needing attention: participation, methodologies, institutionalisation and scaling-up, and documentation.

\section{Participation}

Some questions related to participation have been mentioned but there are many others that remain unresolved. How do we decide who gets involved - and on what basis are people invited to join PM\&E processes? What degree of involvement is expected - and what is realistic? How can decision-making power be shared - and negotiated? Under what conditions can PM\&E help achieve expectations of empowerment? What are gender needs and implications of PM\&E, and how do we build them into the process?

Participatory M\&E is a social, cultural and political process. As more and different stakeholder groups co-operate to keep track of change together, they will need to make compromises on whose indicators count more, what methods are feasible and considered valid, who is involved in which way, etc. One particularly important question is that of who interprets the information and uses the findings (Bandre, this issue). If $\mathrm{PM} \& \mathrm{E}$ is used as a strategy for empowering marginalised groups and people, revealing problems, gaps, and errors will not necessarily be viewed kindly by those with more power. It is inevitable that not all the different perspectives will merge smoothly or can even be reconciled.

Furthermore, seeking greater participation in $\mathrm{M} \& \mathrm{E}$ is essentially a strategy for making decision-making a more democratic process. Therefore PM\&E is a social process of bringing people together in new ways, a cultural process of coming to understand different views, and a political process of sharing decisions. As greater stakeholder involvement in $\mathrm{M} \& \mathrm{E}$ brings together those with more and less power, it also requires a look at the ethics of coping with unpredictable outcomes that do not necessary please the stakeholder group(s) with power over others. What preconditions for PM\&E can help it achieve expectations of empowerment?

\section{Methodologies}

Innovations with methods, sequences, and combinations of methodologies are also forcing new questions. For example, what is needed to combine the need for participation, flexibility and a learning agenda with scientific rigour? When do we use more conventional forms of monitoring and evaluation, and more participatory forms - and how can we combine them? In the absence of set standards and definitions, how can we identify examples of best practice from which to learn? How do we guarantee not falling into the trap of developing an overly complex approach that demands too much time and gathers irrelevant information?

Many methodological questions relate to the use of indicators. The literature on monitoring and evaluation emphasises the importance of selecting precise indicators carefully as it is easy to identify too many, and choose ambiguous or irrelevant ones. However, the growing experiences with participatory $\mathrm{M} \& \mathrm{E}$, which involve more and different groups of people, are also stressing the importance of ensuring that indicators meet the different information requirements of those involved. Furthermore, indicators should ideally look at short and longer term changes; local and broader scale changes; the general development process and concrete initiatives; quantitative and qualitative information; and tangible and intangible impacts (Torres; Abes this issue).

With so many information needs, selecting indicators becomes a difficult task. How do we guide this process? Rai (this issue) offers one example of how forestry management indicators were determined by collectively looking at the objectives of joint forest management, and Abes (this issue) discusses a similar approach. Who should/can be involved and for whom is the information? If one group decides on what should be collected, will other groups also find that relevant or credible evidence of change? Torres describes that bringing the different perspectives on what 
should be monitored and evaluated together is an essential process that helps build consensus about the vision for development. However, flexibility about the methods is required because development visions change, information needs shift, and therefore indicators will also change.

\section{Institutionalisation}

Many of the more complex challenges of $P M \& E$ arise when organisations decide to adopt the principles and practices and find that this has widespread repercussions. As mentioned above, the interest in PM\&E is growing as organisations are realising that they need to learn more about internal processes and external impacts if they want to perform better (Bandre; Symes and Jasser, this issue).

Yet opening up a development programme or project to comments from a wider group of people can be threatening and provoke resistance to change, and may well only be possible under certain conditions (see Box 6). How can flexible and context-specific PM\&E processes be integrated with rigid and standardised project cycles? And how can it be replicated? How do we reconcile learningdriven $\mathrm{PM} \& \mathrm{E}$ with $\mathrm{M} \& \mathrm{E}$ that is dominated by upward-accountability and 'bean-counters' (especially economists and accountants)? What strategies can we use to overcome organisational resistance to letting go of controlling the process? What are the real costs of PM\&E - and can this investment of time and money be sustained? How can we build capacity when this is new for everyone? How do we deal with frequent changes in complex institutional linkages?

Transferring responsibilities (Rai, this issue) and creating new understanding that arises from different people using a wider range of indicators can provoke an entire restructuring of some organisations. Such changes are only possible if time is allocated for reflection within organisations and between partners. Also critical is the importance of linking monitoring and evaluation into the whole project or programme cycle, so that new plans are built on findings from M\&E (Bandre; Torres, this issue).

\section{FACTORS THAT HELP PARTICIPATORY MONITORING AND EVALUATION}

Participatory M\&E is easier if the context....

- accepts evaluation as an internal need and responsibility, and not threatening

- accepts learning through experience - or 'failing forward' (Chambers, 1997)

- understands the need for partnerships between sectors and disciplines, especially openness towards involving social sciences

- $\quad$ works in decentralised institutions

- is open to using qualitative indicators

- includes funding agencies willing to experiment, and 'champions' (or advocates) for PM\&E in the right places and levels

- includes those with some skills in conflict resolution

- understands participation as a democratic, not extractive, process

- includes high-level people who have the political will to see PM\&E as an empowerment process

- includes a process of carefully defining who 'the community' is, to avoid missing key people

- has established community awareness of the PM\&E process

- is set within supportive legal/constitutional frameworks (so not in politically repressive situations)

- includes people's organisations who trust and have confidence in people's potential

- has access to positive examples and skilled facilitators

- includes a local community co-ordinator or other liaison person/institution

- allows enough time to develop the PM\&E process

- ensures prompt feedback/use of PM\&E findings 
Unfortunately, many working with PM\&E have been hindered by non-participatory aspects of their organisations or contexts (Symes and Jasser, this issue). Clearly, widereaching participatory processes are more likely in less hierarchical organisations/cultures. Other institutional issues to consider include how donor policies, such as their insistence on cost-effectiveness within social development projects/programmes, can hinder PM\&E; and how imposing $\mathrm{PM} \& \mathrm{E}$ can be counterproductive. In countries with policies of participatory planning or decentralisation (for example Bolivia and Uganda), PM\&E may be more acceptable.

Participatory M\&E can only spread with trained people and trainers. Yet there are few able to take on this new task. Capacities need to be built at different levels, to raise general awareness and train skills. But skills have to be developed not only in the use of PM\&E methods but the process in general. Many of the PM\&E experiences so far have been initiated by external organisations and individuals. Unless skills and interest take root locally, sustainable PM\&E is out of the question. As information needs will continually change, and even partners will be changing, capacity building also means that the different stakeholder groups need to be able to adapt PM\&E over time.

Rai and Torres (this issue) describe how, in both Nepal and Ecuador, encouraging continual adaptation is crucial to enable people who have been drawn into monitoring and evaluation to make it their own. Capacities are needed to help organisations deal with changes (Symes and Jasser, this issue); to motivate users to update and innovate (Rai, this issue); to understand concepts, principles, methods and working relationships (Bandre, Abes this issue). Capacity building is about sustaining processes, which means clarity about what 'sustainable PM\&E' means. Is it the indicators, the methods, the feedback process, the capacity to implement, or the ability to continue evolving the system that is sustained? Each requires a different focus of capacity building.

\section{Documentation}

The current lack of documentation is a key obstacle to more innovative and wider use of all that PM\&E appears to offer. Who should do this documentation - and who will benefit from it? Why is there such little documentation of PM\&E processes - and most in a project context? In what form should information be shared - visual, written, through drama?

Some of these gaps will be filled by several initiatives related to the Philippines workshop. The workshop proceedings will be available by the end of February from IIRR ${ }^{1}$. These will include a section on Priority Action Plans which describe concrete steps to be taken in these specific areas, and identify the lead people/organisations. A book on PM\&E will be published this year (to be announced in the PLA Notes), and a Resource Guide on PM\&E Methods is being planned. Various training initiatives are in the pipeline, as are several research projects that look at methodological and institutional 'best practice' and how to merge or adapt other methodologies (included in the workshop proceedings).

\section{- Moving forward}

Now that many agencies, organisations, and individuals are settling into participatory forms of appraisal and planning, all eyes seem to be looking towards participatory monitoring and evaluation as the next area of methodological innovation. But amidst the growing number of exciting experiences, many fundamental questions and challenges have appeared. We need to monitor and evaluate these PM\&E processes as they mature to learn more. So far we know that the image of PM\&E as a neat toolbox of indicators and methods, a simple calendar, and clear tasks hides what is a dynamic and political process. As contexts change, so does the process of participatory monitoring and evaluation. New stakeholder groups emerge and some disappear, objectives change and therefore indicators change, methods continually evolve, and the timing of monitoring is always being re-negotiated.

1 Contact Mae S. Arevalo/Angie Ibus, PME Workshop Secretariat, IIRR, Silang, Cavite, Philippines. Fax: +63-46-414 2420. 
At the workshop, one person commented: 'PM\&E is a journey, not a destination. It is a process, not an activity.' We hope that this issue of the PLA Notes is one source of information to inspire that journey.

- Irene Guijt, c/o IIED, Email: sustag@iied.org, Mae Arevalo and Kiko Saladores, IIRR, Dr. YC James Yen Center, Biga, Silang, Cavite, The Philippines. Email: iirr@phil.gn.apc.org

NOTES
The workshop was hosted and organised by
the International Institute for Rural
Reconstruction (IIRR), Philippines. The
International Steering Committee comprised:
Angie Ibus, Julian Gonsalves, Marisse Espineli
and Mae Arevalo (IIRR, The Philippines); John
Gaventa, Marisol Estrella and Jutta Blauert
(Institute for Development Studies, UK); Dindo
Campilan (UPWARD, The Philippines); Reme
'Pong' Clemente (KAISAHAN, The
Philippines); Roger Ricafort (Oxfam Hong
Kong); Deb Johnson (Sikiliza International,
Uganda); and Irene Guijt (IIED, UK).

\section{ACKNOWLEDGEMENTS}

The workshop was funded by the International Development Research Centre (Canada) and Swiss Development Cooperation (SDC), with additional support from IDS (UK) and the Department for International Development (UK).

Irene Guijt would like to thank the Department of Forestry, Australian National University for logistical support.

\section{REFERENCES}

Abbot, J. and I. Guijt. 1998. Changing Views on Change: Participatory Approaches to Monitoring the Environment. Sustainable Agriculture and Rural Livelihoods Discussion Paper Number 2. IIED, UK.

Alexandra J., S. Haffenden, and T. White. 1996. Listening to the Land. A Directory of Community Environmental Monitoring Groups in Australia. Australian Conservation Foundation, Fitzroy.

Chambers, R. 1997. Whose Reality Counts? Intermediate Technology Publications, London.

Chatterjee, A. 1997. An Approach Towards Assessing Progress Towards
Sustainability: The Tumkur (India) experience. Paper written for the International Workshop on

Participatory Monitoring and Evaluation, Cavite, the Philippines, Nov 22 - 29, 1997.

Davies, R. 1995. An evolutionary approach to facilitating organizational learning: An experiment by the Christian Commission for Development in Bangladesh (CCDB). Paper written for ODI-CDS workshop 67 April 1995

The Potential for Process Monitoring in Project Management and Organizational Change'.

Estrella, M. and J. Gaventa. 1997. Who Counts Reality? Participatory Monitoring and Evaluation: $A$ Literature Review. Working draft. IDS, UK.

Kaul Shah, M. Participatory Monitoring: Some Reflections. Paper presented at the ODA Social Development Colloquium, London, December 1995.

Sewagudde, J., G. Mugisha, R. Ochen, and G. Mukasa. 1997. Mixing and matching Methodologies in Redd Barna Uganda. In: PLA Notes 28, pp79-84. IIED, London. 